Volume 10 Issue 3, July-September 2016: pp. 413-. Copyright (c) 2015-2016 FIAT JUSTISIA. Faculty of Law, Lampung University, Bandarlampung, Lampung, Indonesia. ISSN: 1978-5186 | e-ISSN: 2477-6238.

Open Access: http://jurnal.fh.unila.ac.id/index.php/fiat

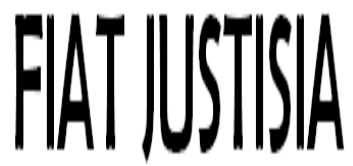

Fiat Justisia is licensed under a Creative Commons Attribution 4.0 International License, which permits unrestricted use, distribution, and reproduction in any medium, provided the original work is properly cited.

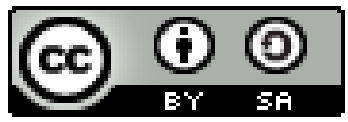

\title{
PERIZINAN PENGGUNAAN TENAGA KERJA ASING DENGAN BERLAKUNYA MASYARAKAT EKONOMI ASEAN
}

\section{Licensing Use Foreign Labor on Applying ASEAN Economic Community}

\author{
May Yanti Budiarti \\ Badan Pengawas Pemilihan Umum Provinsi Lampung \\ email: mayyanti79@gmail.com
}

\begin{abstract}
In early 2016 the ASEAN countries have officially implement the commitments which named the Asean Economic Community (AEC). The spirit of the stretcher is the spirit of ASEAN economic integration. In the $M E A$ of skilled labor in the region is given the freedom to work anywhere in the ASEAN region. However, each country still has licensing restrictions. Law No. 13 of 2003 be the main pillars that govern the licensing of foreign workers, especially in Chapter VIII started to subsection 42 through subsection 49. That should be of concern is subsection 45 paragraph (1a) requires manpower Indonesian citizen who becomes the companion of foreign. The presence of foreign workers in the MEA era is no longer in the context of knowledge transfer and technology transfer, but TKA comes with the spirit of ASEAN economic integration. Or in other words the freedom to work wherever the foreign workers want to work. Employers of foreign workers required to implement the education and training for workers who become facilitators TKA. But employers are reluctant. Because, there are loopholes in our licensing that would allow foreign workers to work continuously in Indonesia. By regulation, of course, the implementation of the MEA are now in violation of the contents of Law 13/2003 on Manpower. Another major problem associated MEA is the readiness of Indonesian Labor competence and the availability of jobs for Indonesian workers.
\end{abstract}

Keywords: Foreign Workers, AEC, Economic Integration 


\begin{abstract}
Abstrak
Di awal Tahun 2016 Negara-negara ASEAN sudah resmi melaksanakan komitmen bersama yang bernama Masyarakat Ekonomi Asean (MEA). Semangat yang di usung adalah semangat integrasi ekonomi ASEAN. Di dalam MEA tenaga kerja terampil yang ada di kawasan ini di berikan kebebasan untuk berkerja di mana saja di kawasan ASEAN. Namun masingmasing negara tetap memiliki batasan perizinan. UU Nomor 13 Tahun 2003 menjadi pilar utama yang mengatur perizinan TKA terutama di Bab VIII mulai Pasal 42 sampai dengan Pasal 49. Yang harus menjadi perhatian adalah Pasal 45 ayat (1a) yang mewajibkan adanya tenaga kerja warga negara Indonesia yang menjadi pendamping. Kehadiran TKA di era MEA ini tidak lagi dalam konteks alih pengetahuan (transfer of knowledge) dan alih tehnologi (transfer of technology), tetapi TKA hadir dengan dengan semangat integrasi ekonomi ASEAN. Atau dengan kata lain kebebasan bekerja dimanapun TKA tersebut ingin bekerja. Pengusaha pengguna TKA wajib melaksanakan pendidikan dan pelatihan bagi TKI yang menjadi tenaga pendamping TKA. Namun pengusaha seringkali enggan. Pasalnya, ada celah dalam perizinan kita yang menungkinkan TKA bisa bekerja terus di Indonesia. Secara regulasi, tentunya pelaksanaan MEA saat ini sudah melanggar isi UU 13/2003 tentang Ketenagakerjaan. Masalah utama lain terkait MEA adalah kesiapan kompetensi Tenaga Kerja Indonesia dan ketersediaan lapangan kerja buat pekerja Indonesia.
\end{abstract}

Kata Kunci: TKA, MEA, integrasi ekonomi

\title{
A. Pendahuluan
}

Di tinjau dari segi filosofis, negara sebagai organisasi mempunyai tujuan dan tujuan ini juga harus mempunyai kekuatan. Memperhatikan Alinea keempat Pembukaan UUD NRI 1945 secara jelas dinyatakan bahwa negera ini dibentuk dengan tujuan untuk meningkatkan kesejahteraan rakyat. Hal ini juga menjadi tujuan dirumuskannya peundang-undangan perizinan TKA yang bertujuan untuk mempercepat terwujudnya kesejahteraan masyarakat melalui peningkatan, pelayanan, pemberdayaan, dan peran serta masyarakat. Untuk mewujudkan tujuan negara tersebut negara sebagai pemegang mandat dari rakyat bertanggungjawab menyelenggarakan perizinan TKA dan mengedepankan kepentingan rakyat Indonesia.

Secara sosiologis, terdapat fakta yang terjadi di sektor ketenaga kerjaan, yaitu adanya tiga permasalahan utama yang dapat mempengaruhi daya saing tenaga kerja, yaitu :

1. Persoalan kesempatan kerja yang terbatas.

2. Rendahnya kualitas angkatan kerja.

3. Masih tingginya tingkat pengangguran. 
Fakta-fakta di atas, jelas harus ada upaya untuk selalu menjaga kondisi ketenagakerjaan yang kondusif di Indonesia. Jangan sampai undangundang perizinan TKA merugikan bahkan menyingkirkan TKI. Dari sisi yuridis, adanya berbagai persoalan ketenagakerjaan ditambah dengan bergabungnya Indonesia ke dalam Masyarakat Ekonomi Asean (MEA), permasalahan perizinan TKA harus di perhatikan dengan serius.

Masyarakat Ekonomi ASEAN (MEA) adalah integrasi ekonomi ASEAN dalam menghadapi perdagangan bebas antar negara ASEAN. MEA memiliki pola mengintegrasikan ekonomi ASEAN dengan cara membentuk sistem perdagangan bebas atau free trade antara negara-negara anggota ASEAN. Penggunaan TKA tidak lain dimaksudkan untuk meningkatkan kemampuan dan pengetahuan sumber daya manusia dalam negeri, dalam jangka waktu tertentu, diharapkan TKA dapat alih teknologi khususnya transfer of knowledge dan telah dikuasai atau sekurang-kurangnya dipahami dengan baik oleh tenaga kerja dalam negeri.

\section{B. Pembahasan}

Agar pengendalian TKA berjalan sesuai dengan tujuan negara, yaitu mempercepat terwujudnya kesejahteraan masyarakat melalui peningkatan, pelayanan, pemberdayaan, dan peran serta masyarakat. Dan juga agar selalu terjaga kondisi ketenagakerjaan yang kondusif di dalam negeri, maka perizinan dalam pengandalian TKA harus memiliki 5 (lima) fungsi, yaitu:

1. Mengarahkan aktivitas-aktivitas yang dapat dilakukan oleh TKA.

2. Negara mencegah dampak negatif kehadiran TKA terhadap lingkungan sosial

3. Keinginan melindungi objek-objek tertentu.

4. Hendak membagi yang sedikit.

5. Mengarahkan dengan menyeleksi orang-orang dan aktivitas, yang harus memenuhi syarat tertentu

Berangkat dari pembatasan penggunaan TKA di Indonesia guna melakukan alih pengetahuan dan teknologi demi meningkatkan kemampuan dan pengetahuan sumber daya manusia dalam negeri (TKI) serta pendayagunaan TKI secara optimal, berdasarkan UU 13/2003 dibagi menjadi 3 (tiga) cara pembatasan. Sebagaimana diatur pada Bab VIII pasal 42 hingga 49 UU 13/2003, ketentuan mengenai pembatasan penggunaan TKA terdiri dari 3 (tiga) kaedah hukum yang bersifat menyuruh atau suruhan (gebod), bersifat melarang atau larangan (verbod), dan bersifat memperbolehkan atau kebolehan (mogen). ${ }^{1}$

\footnotetext{
${ }^{1}$ Macam kaedah hukum jika ditinjau dari isinya. Jika dilihat dari sifat, maka kaedah hukum dapat bersifat imperatif atau memaksa dan secara a priori wajib ditaati, dan fakultatif yang sifatnya tambahan atau tidak secara a priori wajib itaati (kebolehan). Purbacaraka, Purnadi
} 
Pemberi kerja juga diwajibkan untuk memiliki RPTKA yang sifatnya melekat dengan izin mempekerjakan TKA tersebut, yaitu sebagai syarat dikeluarkannya IMTA. ${ }^{2}$ Adapun sasaran pemberian IMTA pada UU 13 Tahun 2003 adalah perlindungan TKI melalui pengendalian penggunaan TKA sesuai dengan kebutuhan sehingga dalam mempekerjakan TKA perlu dipertimbangkan secara teliti dan mendalam menyangkut 2 (dua) aspek, yaitu: ${ }^{3}$ Aspek manfaat (prosperity); dan Aspek keamanan (security).

Terdapat empat hal yang akan menjadi fokus MEA pada tahun 2015 yang dapat dijadikan suatu momentum yang baik untuk Indonesia. Pertama, negara-negara di kawasan Asia Tenggara ini akan dijadikan sebuah wilayah kesatuan pasar dan basis produksi. Dengan terciptanya kesatuan pasar dan basis produksi maka akan membuat arus barang, jasa, investasi, modal dalam jumlah yang besar, dan skilled labour menjadi tidak ada hambatan dari satu negara ke negara lainnya di kawasan Asia Tenggara.

Kedua, MEA akan dibentuk sebagai kawasan ekonomi dengan tingkat kompetisi yang tinggi, yang memerlukan suatu kebijakan yang meliputi competition policy, consumer protection, Intellectual Property Rights (IPR), taxation, dan E-Commerce. Dengan demikian, dapat tercipta iklim persaingan yang adil; terdapat perlindungan berupa sistem jaringan dari agen-agen perlindungan konsumen; mencegah terjadinya pelanggaran hak cipta; menciptakan jaringan transportasi yang efisien, aman, dan terintegrasi; menghilangkan sistem Double Taxation, dan; meningkatkan perdagangan dengan media elektronik berbasis online ${ }^{4}$.

Ketiga, MEA pun akan dijadikan sebagai kawasan yang memiliki perkembangan ekonomi yang merata, dengan memprioritaskan pada Usaha Kecil Menengah (UKM). Kemampuan daya saing dan dinamisme UKM akan ditingkatkan dengan memfasilitasi akses mereka terhadap informasi terkini, kondisi pasar, pengembangan sumber daya manusia dalam hal peningkatan kemampuan, keuangan, serta teknologi.

Keempat, MEA akan diintegrasikan secara penuh terhadap perekonomian global. Dengan dengan membangun sebuah sistem untuk

dan Soekanto, Soerjono. (1993) Perihal Kaedah Hukum, cet. 6. Bandung: PT Citra Aditya Bakti, p. 34-38.

${ }^{2}$ Lihat Pasal 43 UU 13/2003 jo. Pasal 3 ayat (1) Kepmenakertrans No. 173/Men/2000, Pasal 4 ayat (1) huruf a Kepmenakertrans No. 20/Men/III/2004, Pasal 2 ayat (1) huruf a Permankertrans No. Per-15/Men/IV/2006, Pasal 3 ayat (2) Permenakertrans No. Per.02/Men/III/2008.

3 Departemen Tenaga Kerja dan Transmigrasi Republik Indonesia. (2003). Pemahaman Pasal-Pasal Utama Undang-Undang Ketenagakerjaan (UU No. 13/2003). Jakarta: Departemen Tenaga Kerja dan Transmigrasi Republik Indonesia, p. 13.

${ }^{4}$ Peluang, Tantangan, Dan Risiko Bagi Indonesia Dengan Adanya Masyarakat Ekonomi Asean, http://crmsindonesia.org/knowledge/crms-articles/peluang-tantangan-dan-risiko-ba gi-indonesia-dengan-adanya-masyarakat-ekonomi, (diakses pada tanggal 21/10/2016). 
meningkatkan koordinasi terhadap negara-negara anggota. Selain itu, akan ditingkatkan partisipasi negara-negara di kawasan Asia Tenggara pada jaringan pasokan global melalui pengembangkan paket bantuan teknis kepada negara-negara Anggota ASEAN yang kurang berkembang. Hal tersebut dilakukan untuk meningkatkan kemampuan industri dan produktivitas sehingga tidak hanya terjadi peningkatkan partisipasi mereka pada skala regional namun juga memunculkan inisiatif untuk terintegrasi secara global.

Para pengusaha di Indonesia di khawatirkan akan cenderung merekrut TKA dibandingkan pekerja Indonesia. Selain masalah kompetensi, para pengusaha akan lebih suka merekrut TKA karena TKA, sesuai Pasal 42 ayat (4) UU 13/2003, dipekerjakan di Indonesia dengan jangka waktu tertentu. Ini artinya tidak ada TKA yang menjadi pekerja tetap, yang bila di-PHK akan memperselisihkannya ke Pengadilan Hubungan Industrial (PHI) dan Mahkamah Agung (MA).

Karena TKA dipekerjakan dengan jangka waktu tertentu maka TKA akan lebih mudah di-PHK karena alasan habis masa kerjanya. Dibandingkan dengan pekerja Indonesia yang bisa dikontrak tetapi dalam batas waktu tertentu dan pekerjaan tertentu seperti diamanatkan Pasal 59 UU 13/2003, dan bila pengusaha melanggar pasal tersebut maka pekerja tersebut otomatis menjadi pekerja tetap, maka pengusaha akan lebih senang merekrut TKA dibandingkan pekerja Indonesia.

\section{Penutup}

\section{Simpulan}

Fungsi izin dalam pengendalian TKA adalah mengarahkan aktivitasaktivitas yang dapat dilakukan oleh TKA, yaitu pembatasan penggunaan TKA pada jabatan tertentu, pembatasan hanya pada pekerjaan tertentu dan juga pembatasan masa kerja, mencegah dampak negatif kehadiran TKA terhadap lingkungan sosial dalam hal ini budaya asing yang dibawa oleh TKA, melindungi TKI dalam penekanan sebagai agen transfer of knowledge dan transfer of technologi, tidak mempersempit lapangan kerja bagi TKI, memperketat persyaratan masuknya TKA, dan meningkatkan daya saing TKI hingga dapat mempunyai kualitas atau keahlian yang sebanding dengan TKA. Dari ke lima fungsi tersebut belum ada satupun yang bisa berjalan dengan baik karena masih terdapat banyak kekurangan yang harus di benahi oleh semua pihak yang terkait. Apalagi dengan semakin majunya teknologi, pengunaan TKA tidak membutuhkan kehadirkan secara fisik. Pekerjaan tertentu sudah bisa menggunakan internet, baik untuk instruksi maupun hasil dari pekerjaannya. Hal ini membuat semakin sulit untuk mengawasi penggunaan TKA. 


\section{Saran}

Berikut adalah beberapa saran kepada pemerintah yang terkait agar perizinan TKA tetap bisa bermanfaat bagi negara dengan tetap memberikan perlindungan dan kenyamanan bagi TKI

a. Semangat kebebasan tenaga kerja yang di usung oleh MEA dalam pelaksanaannya di dalam negeri harus tetap memperhatikan amanat perundang-undangan, yaitu alih pengetahuan (transfer of knowledge) dan alih tehnologi (transfer of technology). Jangan sampai MEA tidak memberdayakan tenaga kerja lokal yang ada, diperlukan peraturan khusus untuk mengatur penggunaan TKA dengan berlakunya MEA.

b. UU 13/2003 masih membuka peluang bagi pemberi kerja untuk dapat terus menggunakan TKA tanpa berbatas waktu. Celah tersebut adalah Pasal 59 UU 13/2003. Pengusaha tinggal melanggar pasal tersebut maka, otomatis TKA menjadi pekerja tetap. Untuk perlindungan tenaga lokal, maka pasal ini perlu di amandemen.

c. Di era MEA seperti saat ini, harusnya pemerintah tidak hanya fokus kepada membangun infrastrukturnya saja. Namun lebih kepada jumlah dan kualitas kompetensi pekerja Indonesia yang telah sesuai dengan standar yang ditetapkan MEA.

\section{Daftar Pustaka}

\section{A. Buku}

Departemen Tenaga Kerja dan Transmigrasi Republik Indonesia. (2003).

Pemahaman Pasal-Pasal Utama Undang-Undang Ketenagakerjaan (UU No. 13/2003), Jakarta: Departemen Tenaga Kerja dan Transmigrasi Republik Indonesia.

Purbacaraka, Purnadi dan Soekanto, Soerjono. (1993). Perihal Kaedah Hukum. Cet. 6. Bandung: PT Citra Aditya Bakti.

\section{B. Sumber Lain}

Undang-Undang No. 3 Tahun 1958 tentang Penempatan Tenaga Kerja Asing.

Undang-Undang No. 13 Tahun 2003 tentang Ketenagakerjaan.

Undang-Undang No. 2 Tahun 2004 tentang Penyelesaian Perselisihan Hubungan Industrial.

http://crmsindonesia.org/knowledge/crms-articles/peluang-tantangan-danrisiko-bagi-indonesia-dengan-adanya-masyarakat-ekonomi, (diakses 21 Oktober 2016). 